RACIC 6(1) (2021)
JNIVERSITAS
ABDURRAB

\title{
EVALUASI KINERJA STRUKTUR BANGUNAN BETON BERTULANG DI TANAH KHUSUS BERDASARKAN ANALISIS PUSHOVER
}

\author{
Halimatusadiyah $^{1}$, Reni Suryanita ${ }^{2}$, dan Muhamad Yusa ${ }^{3}$ \\ Program Studi Pascasarjana Teknik Sipil, Fakultas Teknik Sipil, Universitas Riau \\ Kampus Bina Widya Jl. HR Soebantas KM. 12,5, Pekanbaru \\ Telp. (0761) 52324 \\ E-mail : halimatusadiyah6599@grad.unri.ac.id
}

Info Artikel

Sejarah Artikel:

Diterima : 20 Desember 2020

Disetujui :29 Juni 2021

Dipublikasikan : 30 Juni 2021

Keywords:

Tanah khusus ; Analisis pushover; Kinerja struktur
Tanah khusus merupakan profil lapisan tanah yang rawan dan berpotensi likuifaksi, yang membutuhkan investigasi geoteknik spesifik dan analisis respons spesifik-situs. Salah satu faktor pengaruh desain struktur bangunan tahan gempa adalah kondisi lapisan tanah dan bentuk konfigurasi dari struktur yang dianalisis. Penelitian ini bertujuan untuk mengevaluasi kinerja struktur bangunan beton bertulang di tanah khusus berdasarkan metode analisis pushover. Analisis pushover adalah metode statis non-linear dimana struktur mengalami pembebanan gravitasi dan pola beban lateral yang dikendalikan perpindahan monotonic yang terus meningkat melalui perilaku elastik dan inelastik hingga kondisi akhir tercapai. Hasil penelitian menunjukan bahwa tingkat kinerja struktur analisis pushover berdasarkan ATC-40 struktur termasuk dalam level kategori Damage Control.

Kata Kunci: Tanah khusus, analisis pushover, kinerja struktur.

\begin{abstract}
Site class $F$ is a profile of soil layers that are prone to liquefaction, that require specific geotechnical investigations and site-specific response analysis. One of the factors that influence design of earthquake-resistant the building structures is condition of the soil layer and and analysis structure. This research to evaluate the performance of reinforced concrete structures on site class $F$ besed on the pushover analysis method. Pushover analysis is a non-linear static method in which a structure is subjected to gravitational loading and a lateral load pattern controlled by monotonic displacement which continues to increase through elastic and inelastic behavior until final conditions are reached. The results showed that the performance level of the pushover analysis structure based on the ATC-40 structure is included in the Damage Control category level.
\end{abstract}

Keywords : Site class $F$, pushover analysis, structure performance. 


\section{PENDAHULUAN}

Analisis pushover adalah metode statis non-linear dimana struktur mengalami pembebanan gravitasi dan pola beban lateral yang dikendalikan perpindahan monotonic yang terus meningkat melalui perilaku elastik dan inelastik hingga kondisi akhir tercapai. Tanah khusus adalah profil lapisan tanah yang rawan dan berpotensi likuifaksi, yang membutuhkan investigasi geoteknik spesifik dan analisis respons spesifik-situs. Berdasarkan data yang dihimpun dari BMKG tercatat kejadian gempa di Indonesia telah terjadi likuifaksi akibat gempa bumi, yaitu Gempa Sulawesi Tengah berkekuatan 7,4 $\mathrm{M}_{\mathrm{W}}$ pada tanggal 28 September 2018, dan Gempa Lombok berkekuatan 7,0 $\mathrm{M}_{\mathrm{W}}$ pada tanggal 5 Agustus 2018. Penelitian ini bertujuan untuk mengurangi dampak resiko kerusakan struktur bangunan akibat gempa bumi, terutama pada daerah-daerah yang memiliki lapisan tanah yang tidak memadai untuk pembangunan gedung bertingkat, dengan cara mengevaluasi kinerja struktur bangunan beton bertulang di tanah khusus menggunakan metode analisis pushover.

Penelitian mengenai Tanah Khusus (SF) belum banyak yang meneliti dikarenakan tidak adanya nilai parameter klasifikasi situs untuk Tanah Khusus (SF) yang signifikan. Namun penelitian terkait dengan evaluasi kinerja struktur yang pernah dilakukan oleh Sultan, M. A (2016) melakukan penelitian mengenai evaluasi kinerja struktur beton bertulang tahan gempa dengan analisis pushover, menyatakan bahwa evaluasi kinerja dapat memberikan informasi sejauh mana gempa akan mempengaruhi struktur bangunan gedung. Menurut Arifin, Z., dkk (2016) melakukan penelitian analisis struktur gedung POP Hotel terhadap beban gempa dengan metode pushover analysis, menyatakan bahwa kinerja bangunan Gedung POP Hotel mengalami kerusakan dengan level kinerja Damage Control, dengan perpindahan sebesar 0,47 meter pada arah Y dan gedung mengalami keruntuhan beam sway. Sedangkan menurut Chin, et al. melakukan penelitian evaluasi respons seismik untuk kelas situs tanah khusus menggunakan metode linear ekivalen dan kode komputer nonlinear, jika analisis respons situs digunakan untuk tegangan geser tanah dan evaluasi regangan, itu harus dilakukan dengan rangkaian time history gempa yang mewakili bahaya seismik pada situsnya.

\section{TINJAUAN PUSTAKA}

\section{Kinerja Struktur}

Tingkat kinerja sebuah bangunan menunjukan kondisi bangunan setelah mengalami gempa. Kondisi ini dijelaskan melalui deskripsi kerusakan fisikal yang dialami bangunan, tingkat bahaya akibat kerusakan yang terjadi terhadap pengguna bangunan, dan kemampuan layan bangunan pasca gempa, pada penentuan tingkat layan struktur bangunan berdasarkan FEMA 273 dapat dilihat dari bentuk kurva kapasitas serta kategori tingkat layanan, seperti pada Gambar 1. 


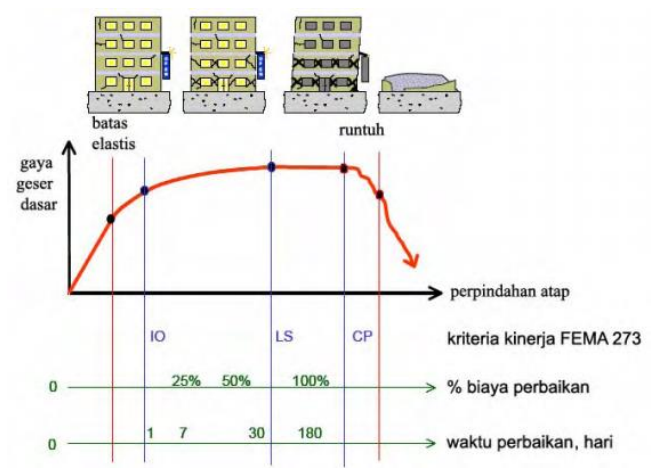

Gambar 1. Ilustasi Tingkat Kinerja Bangunan (FEMA 273, 1997)

Dalam dokumen Applied Tecnology Council 40 (ATC 40), tingkat kinerja bangunan diklasifikasikan menjadi beberapa kategori yaitu sebagai berikut ini :

- Immediate Occupancy, SP-1

- Damage Control, SP-2

- Life Safety, SP-3

- Limited Safety, SP-4

- Structural Stability, SP-5

- $\quad$ Not Considered, SP-6

Menurut ATC-40, batasan rasio drift untuk gedung bertingkat yang dapat digunakan untuk menentukan nilai kinerja bangunan berdasarkan kerusakan yang terjadi. Untuk nilai batasan rasio drift yaitu pada Tabel 1:

Tabel.1. Batasan Rasio Drift Atap (ATC-40, 1996)

\begin{tabular}{c|c|c|c|c}
\hline \multirow{2}{*}{ Parameter } & \multicolumn{4}{|c}{ Perfomance Level } \\
\cline { 2 - 5 } & IO & Damage Control & LS & Struktural Stability \\
\hline Maksimum Total Drift & 0,01 & $0,01 \mathrm{~s} / \mathrm{d} 0,02$ & 0,02 & $0,33 \frac{\mathrm{Vi}}{P i}$ \\
\hline $\begin{array}{c}\text { Maksimum Total } \\
\text { Inelastic Drift }\end{array}$ & 0,005 & $0,005 \mathrm{~s} / \mathrm{d} 0,015$ & No Limit & No Limit \\
\hline
\end{tabular}

Dengan persamaan sebagai berikut ini :

Maksimum Drift $=\frac{D t}{\text { HTotal }}$

Maksimum Inelastic Drift $=\frac{D t-D 1}{\text { HTotal }}$

Dimana :

Dt $=$ Displacement atap

D1 = Displacement lantai 1 (lantai diatas penjepitan lateral)

\section{Tanah Khusus}

Jika salah satu dari kondisi berikut ini terpenuhi, maka situs tersebut harus diklasifikasikan sebagai kelas situs SF, dan dilakukan investigasi geoteknik spesifik dan analisis respons spesifik-situs.

- Tanah yang rawan dan berpotensi mudah likuifaksi, tanah lempung sangat sensitif, dan tanah tersementasi lemah 
- Lempung kadar organik tinggi atau gambut, dengan ketebalan lebih $3 \mathrm{~m}$

- Lempung berplastisitas yang sangat tinggi dengan ketebalan lebih 7,5 m dan indeks plastisitasnya, PI > 75)

- Lempung lunak/setengah teguh, dengan ketebalan $\mathrm{H}>35$ m dengan $\overline{S u}<50 \mathrm{kPa}$.

\section{Analisis Pushover}

Analisis pushover adalah metode statis non-linear dimana struktur mengalami pembebanan gravitasi dan pola beban lateral yang dikendalikan perpindahan monotonic yang terus meningkat melalui perilaku elastik dan inelastik hingga kondisi akhir tercapai. Analisis pushover dapat menampilkan secara visual elemen-elemen struktur yang mengalami kegagalan, sehingga dapat dilakukan pencegahan dengan melakukan pendetailan khusus pada elemen struktur tersebut.

\section{METODE}

Metode pendekatan penelitian yang digunakan bersifat kuantitatif yaitu menganalisis hubungan antara base force dengan displacement (perpindahan) struktur, dan mengumpulkan data sekunder berupa studi pustaka dari literatur ilmiah dan jurnal yang berkaitan dengan analisis gempa struktur, evaluasi kinerja struktur dan data geometri struktur. Metode analisis yang digunakan yaitu metode analisis statis non-linear pushover. Karakteristik tanah khusus yang digunakan yaitu situs lokasi yang memiliki riwayat yang pernah terjadi likuifaksi akibat gempa bumi, seperti Sulawesi Tengah tepatnya di Kota Palu, dikarenakan wilayah tersebut memiliki riwayat pernah tejadi likuifaksi akibat gempa bumi.

\section{Data Geometri Struktur}

Pada desain struktur bangunan ini, digunakan parameter rencana yang dimodelkan pada struktur bangunan. Adapun data geometri dan gambaran struktur secara umum yaitu sebagai berikut :

$\begin{array}{lll}\text { Total Panjang } & =75 \mathrm{~m} \\ \text { Total Lebar } & =24 \mathrm{~m} \\ \text { Tinggi total bangunan } & =41 \mathrm{~m} \\ \text { Tinggi lantai tipikal }(2-10) & =4 \mathrm{~m} \\ \text { Tinggi lantai dasar } & =5 \mathrm{~m} \\ \text { Luas bangunan per lantai } & =1.520 \mathrm{~m}^{2} \\ \text { Material } & =\mathrm{K}-300\left(\mathrm{fc}^{\prime}\right) \quad=24,90 \mathrm{MPa}\end{array}$

Desain geometri pada penelitian ini menggunakan gedung bertingkat dengan elemen struktur yang terbuat dari beton. Bangunan ini direncanakan dengan 10(sepuluh) tingkat dan dapat difungsikan sebagaimana perencanaan bangunan rumah susun.

\section{Permodelan Struktur}

Permodelan struktur yang didesain dapat dilihat pada gambar dibawah ini : 


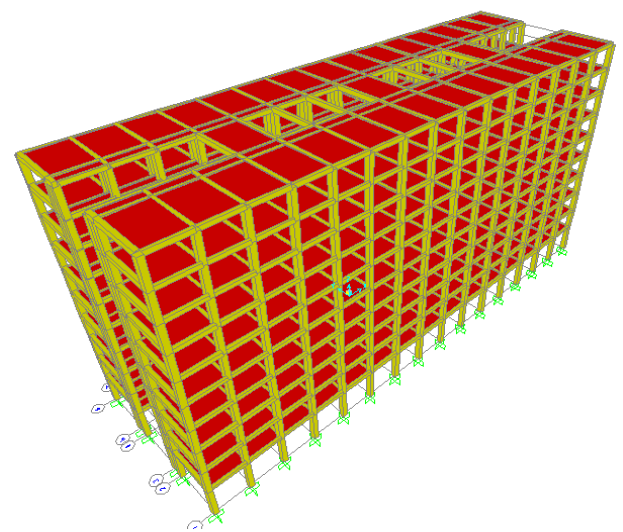

Gambar 2. Permodelan bentuk struktur

\section{HASIL DAN PEMBAHASAN}

Dari output analisis pushover didapatkan kurva kapasitas dari struktur, yang selanjutnya akan dievaluasi kinerjanya dengan menggunakan ATC-40. Kurva kapasitas dari hasil analisis pushover untuk tanah khusus (SF), dari hasil analisis pushover didapatkan step pola beban dorong yang diberikan pada struktur hingga struktur mengalami keruntuhan, dari step pola beban dorong tersebut dapat digambarkan dalam grafik hubungan gaya dan perpindahan terhadap struktur. Adapun step pola beban dorong hasil dari analisis pushover Tabel 2 dan Tabel 3 dibawah :

Tabel 2. Output beban dorong arah X

\begin{tabular}{r|r|r|r|r|r|r|r|r|r|r|r}
\hline Step & $\begin{array}{c}\text { Displacement } \\
(\mathrm{m})\end{array}$ & $\begin{array}{c}\text { Base Force } \\
(\mathrm{kN})\end{array}$ & \multicolumn{1}{|c|}{ A-B } & B-IO & IO-LS & LS-CP & CP-C & C-D & D-E & $>$ E & Total \\
\hline 0 & 0,000102 & 0 & 11056 & 0 & 0 & 0 & 0 & 0 & 0 & 0 & 11056 \\
\hline 1 & 0,009884 & 3312,396 & 11052 & 4 & 0 & 0 & 0 & 0 & 0 & 0 & 11056 \\
\hline 2 & 0,037495 & 12221,347 & 10304 & 752 & 0 & 0 & 0 & 0 & 0 & 0 & 11056 \\
\hline 3 & 0,119679 & 21540,527 & 7748 & 3308 & 0 & 0 & 0 & 0 & 0 & 0 & 11056 \\
\hline 4 & 0,205632 & 27838,59 & 7264 & 3792 & 0 & 0 & 0 & 0 & 0 & 0 & 11056 \\
\hline 5 & 0,308363 & 33552,692 & 7256 & 3800 & 0 & 0 & 0 & 0 & 0 & 0 & 11056 \\
\hline 6 & 0,411636 & 39364,669 & 7248 & 3668 & 140 & 0 & 0 & 0 & 0 & 0 & 11056 \\
\hline 7 & 0,500117 & 44354,295 & 7176 & 2948 & 932 & 0 & 0 & 0 & 0 & 0 & 11056 \\
\hline 8 & 0,589771 & 49159,327 & 6716 & 3044 & 1296 & 0 & 0 & 0 & 0 & 0 & 11056 \\
\hline 9 & 0,678325 & 53535,727 & 6426 & 2998 & 1632 & 0 & 0 & 0 & 0 & 0 & 11056 \\
\hline 10 & 0,761627 & 57484,889 & 6200 & 3204 & 1648 & 4 & 0 & 0 & 0 & 0 & 11056 \\
\hline 11 & 0,806026 & 59429,71 & 6060 & 3292 & 1554 & 150 & 0 & 0 & 0 & 0 & 11056 \\
\hline
\end{tabular}

Tabel 3. Output beban dorong arah Y

\begin{tabular}{r|r|r|r|r|r|r|r|r|r|r|r}
\hline Step & $\begin{array}{c}\text { Displacement } \\
(\mathrm{m})\end{array}$ & $\begin{array}{c}\text { Base Force } \\
(\mathrm{kN})\end{array}$ & \multicolumn{1}{c|}{ A-B } & B-IO & IO-LS & LS-CP & CP-C & C-D & D-E & >E & Total \\
\hline 0 & 0,000102 & 0 & 11056 & 0 & 0 & 0 & 0 & 0 & 0 & 0 & 11056 \\
\hline 1 & 0,000146 & 4764,534 & 11048 & 8 & 0 & 0 & 0 & 0 & 0 & 0 & 11056 \\
\hline 2 & 0,000282 & 19886,799 & 9516 & 1540 & 0 & 0 & 0 & 0 & 0 & 0 & 11056 \\
\hline 3 & 0,000283 & 20061,286 & 9396 & 1660 & 0 & 0 & 0 & 0 & 0 & 0 & 11056 \\
\hline 4 & 0,000283 & 20125,106 & 9344 & 1712 & 0 & 0 & 0 & 0 & 0 & 0 & 11056 \\
\hline 5 & 0,000283 & 20219,214 & 9280 & 1776 & 0 & 0 & 0 & 0 & 0 & 0 & 11056 \\
\hline 6 & 0,000283 & 20323,92 & 9216 & 1840 & 0 & 0 & 0 & 0 & 0 & 0 & 11056 \\
\hline 7 & 0,000281 & 20541,166 & 9148 & 1908 & 0 & 0 & 0 & 0 & 0 & 0 & 11056 \\
\hline 8 & 0,000281 & 20615,723 & 9112 & 1944 & 0 & 0 & 0 & 0 & 0 & 0 & 11056 \\
\hline
\end{tabular}


Halimatusadiyah, Reni Suryanita, Muhammad Yusa / Jurnal Rab Contruction Research 6 (1) (2021)

\begin{tabular}{r|r|r|r|r|r|r|r|r|r|r|r}
\hline 9 & 0,000279 & 20789,736 & 9020 & 2036 & 0 & 0 & 0 & 0 & 0 & 0 & 11056 \\
\hline 10 & 0,000279 & 20848,32 & 8996 & 2060 & 0 & 0 & 0 & 0 & 0 & 0 & 11056 \\
\hline 11 & 0,000279 & 20972,309 & 8964 & 2092 & 0 & 0 & 0 & 0 & 0 & 0 & 11056 \\
\hline 12 & 0,000282 & 21544,585 & 8800 & 2256 & 0 & 0 & 0 & 0 & 0 & 0 & 11056 \\
\hline 13 & 0,000284 & 21799,195 & 8672 & 2384 & 0 & 0 & 0 & 0 & 0 & 0 & 11056 \\
\hline 14 & 0,000285 & 21867,042 & 8632 & 2424 & 0 & 0 & 0 & 0 & 0 & 0 & 11056 \\
\hline 15 & 0,000285 & 21931,491 & 8604 & 2452 & 0 & 0 & 0 & 0 & 0 & 0 & 11056 \\
\hline 16 & 0,000284 & 22068,293 & 8540 & 2516 & 0 & 0 & 0 & 0 & 0 & 0 & 11056 \\
\hline 17 & 0,000284 & 22118,426 & 8524 & 2532 & 0 & 0 & 0 & 0 & 0 & 0 & 11056 \\
\hline 18 & 0,000284 & 22160,526 & 8512 & 2544 & 0 & 0 & 0 & 0 & 0 & 0 & 11056 \\
\hline 19 & 0,000285 & 22256,602 & 8496 & 2560 & 0 & 0 & 0 & 0 & 0 & 0 & 11056 \\
\hline 20 & 0,000287 & 22387,969 & 8460 & 2596 & 0 & 0 & 0 & 0 & 0 & 0 & 11056 \\
\hline 21 & 0,000385 & 30013,873 & 7860 & 3196 & 0 & 0 & 0 & 0 & 0 & 0 & 11056 \\
\hline 22 & 0,000515 & 35939,312 & 7756 & 3140 & 160 & 0 & 0 & 0 & 0 & 0 & 11056 \\
\hline
\end{tabular}

Dari Tabel 2 dan Tabel 3 hasil analisis pushover diatas dapat dilihat nilai gaya yang diberikan pada struktur dan nilai perpindahan yang terjadi pada struktur di tanah khusus, diketahui bahwa pada arah $\mathrm{X}$ bernilai lebih besar perpindahan yang terjadi daripada arah $\mathrm{Y}$, hal ini terjadi dikarenakan bentuk konfigurasi pada arah $\mathrm{X}$ merupakan bentang panjang sedangkan arah $\mathrm{Y}$ merupakan bentang pendek struktur, sehingga saat pemberian beban arah Y cendrung lebih lama untuk berdeformasi namun rentan terhadap perubahan dari perilaku elastis ke non elastis. Mekanisme terbentuknya sendi plastis pada arah X dan arah Y dari Tanah Khusus (SF) dapat dilihat pada Gambar 3 dan Gambar 4 berikut ini :

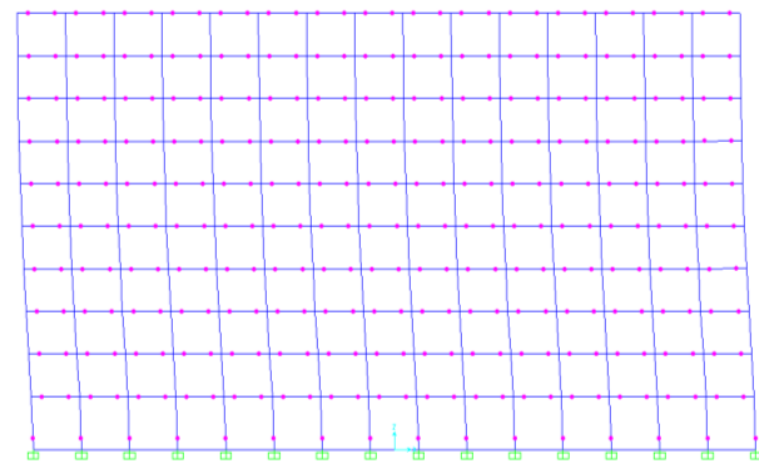

Gambar 3. Push X Step 4

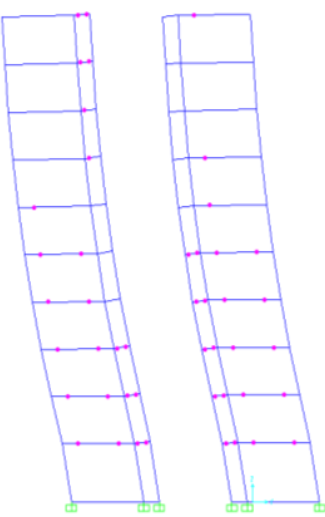

Gambar 4. Push X Step 4 
Dari hasil beban dorong dibuat grafik perbandingan dari base force dan displacement dalam bentuk kurva kapasitas arah X dan arah Y seperti pada Gambar 5 dan Gambar 6 berikut ini :

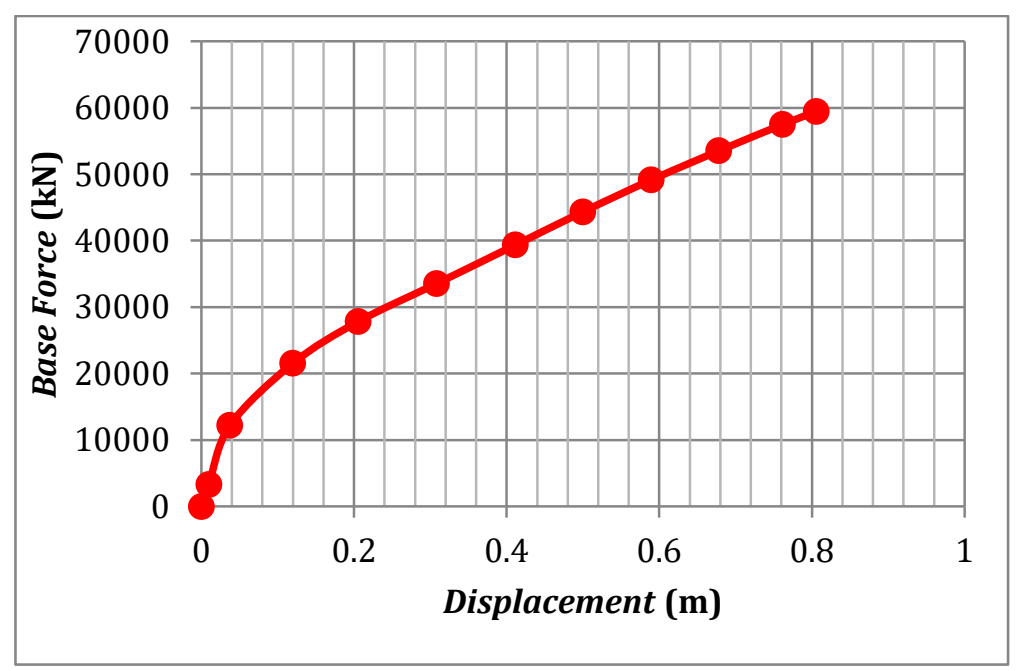

Gambar 5. Kurva Kapasitas Arah X

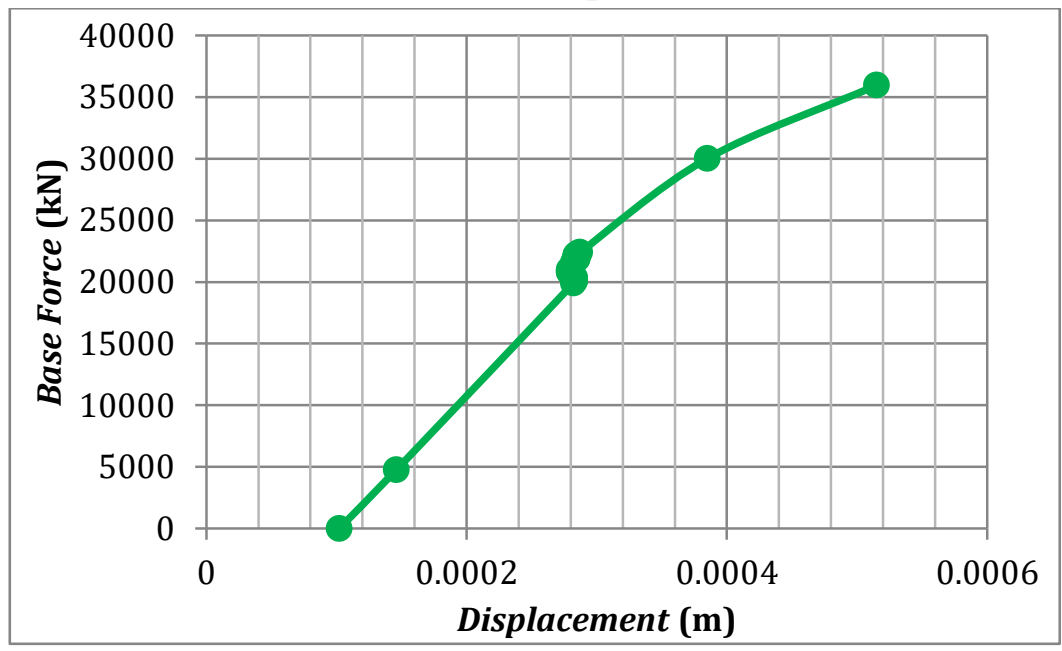

Gambar 6. Kurva Kapasitas Arah Y

Berdasarkan hasil analisis pushover diketahui titik kinerja (performance point) struktur untuk pembebanan arah $\mathrm{X}$ gedung berada di antara step 4 dan step 5, sedangkan titik kinerja (performance point) struktur untuk pembebanan arah $\mathrm{Y}$ gedung mempunyai nilai displacement yang sangat kecil dikarenakan bentuk konfigurasi pada arah $\mathrm{Y}$ merupakan bentang pendek struktur, sehingga saat pemberian beban arah $\mathrm{Y}$ cendrung lebih lama untuk berdeformasi namun rentan terhadap perubahan dari perilaku elastis ke non elastis.

Hasil analisis pushover yang menentukan tingkat kinerja struktur menurut ATC-40 dengan menggunakan Tabel 1, parameter yang diperlukan adalah nilai drift rata-rata tiap lantai dimana total tinggi lantai yaitu 41 meter, seperti pada Tabel 4 berikut ini :

Tabel 4. Tingkat Kinerja Struktur Analisis Pushover Berdasarkan ATC-40

\begin{tabular}{c|c|c|c|c|c}
\hline Tipe Tanah & $\begin{array}{c}\text { Arah } \\
\text { Analisis }\end{array}$ & $\begin{array}{c}\text { Tinggi } \\
\text { Struktur }\end{array}$ & $\begin{array}{c}\text { Nilai Drift } \\
\text { Rata-Rata }\end{array}$ & $\begin{array}{c}\text { Nilai Kinerja } \\
\text { Struktur }\end{array}$ & Keterangan \\
\hline
\end{tabular}


Halimatusadiyah, Reni Suryanita, Muhammad Yusa / Jurnal Rab Contruction Research 6 (1) (2021)

\begin{tabular}{l|c|c|c|c|c}
\hline \multirow{2}{*}{ Tanah Khusus (SF) } & Arah X-X & 41 & 0,4026052 & 0,00982 & Damage Control \\
\cline { 2 - 6 } & Arah Y-Y & 41 & 0,0002964 & 0,000007229 & Immediate Occupancy \\
\hline
\end{tabular}

Maka dari Tabel 4 sesuai dengan nilai yang ditetapkan pada ATC-40 struktur termasuk dalam level kategori Damage Control (DO) SP-2.

\section{SIMPULAN}

Berdasarkan hasil penelitian dari evaluasi kinerja struktur bangunan beton bertulang di tanah khusus berdasarkan metode pushover yang diperoleh maka dapat disimpulkan sebagai berikut :

1. Hasil analisis pushover diatas dapat dilihat nilai gaya yang diberikan pada struktur dan nilai perpindahan yang terjadi pada struktur di tanah khusus, diketahui bahwa pada arah $\mathrm{X}$ bernilai lebih besar perpindahan yang terjadi daripada arah $\mathrm{Y}$, hal ini terjadi dikarenakan bentuk konfigurasi pada arah $\mathrm{X}$ merupakan bentang panjang sedangkan arah Y merupakan bentang pendek struktur, sehingga saat pemberian beban arah Y cendrung lebih lama untuk berdeformasi namun rentan terhadap perubahan dari perilaku elastis ke non elastis.

2. Titik kinerja (performance point) struktur untuk pembebanan arah $\mathrm{X}$ gedung berada di antara step 4 dan step 5, sedangkan titik kinerja (performance point) struktur untuk pembebanan arah Y gedung mempunyai nilai displacement yang sangat kecil.

3. Tingkat kinerja struktur analisis pushover berdasarkan ATC-40 struktur termasuk dalam level kategori Damage Control (DO) SP-2.

\section{DAFTAR PUSTAKA}

Arifin, Z., Suyadi., Sebayang, S., 2015. Analisis Struktur Gedung POP Hotel Terhadap Beban Gempa Dengan Metode Pushover Analysis. JRSSD, 3(3), 427-440.

ATC-40., 1996. Applied Tecnology Council - 40 Seismic Evaluation and Retrofit of Concrete Building Volume 1. California: California Seismic Safety Commision.

Badan Penelitian dan Pengembangan Puslitbang Perumahan dan Permukiman., 2019. Manual Aplikasi Online Spektrum Respons Desain Indonesia 2019. Jakarta.

Badan Standardisasi Nasional., 2019. SNI 1726:2019 Tata Cara Perencanaan Ketahanan Gempa Untuk Struktur Bangunan Gedung dan Non Gedung. Jakarta.

Chin, K. H., 2010. Evaluation of Seismic Response of a Site Class F Site Using Equivalent Linear and Nonlinear Computer Codes. In 5th International Conference on Recent Advances in Geotechnical Earthquake Engineering and Soil Dynamics. San Diego, 2010.

Chopra, A. K ., 2012. Dynamics of Structures Theory and Applications to Earthquake Engineering, 4th ed. California: Prentice Hall.

FEMA 273., 1997. Federal Emergency Management Agency 273 Nehrp Guidelines for The Seismic Rehabilitation of Buildings. Washington, D.C: Federal Emergency Management 
Agency.

Sultan. M. A., 2016. Evaluasi Struktur Beton Bertulang Tahan Gempa Dengan Analisa Pushover. Jurnal Sains, 6(11), 1-8.

Tavio \& Wijaya, Usman., 2018. Desain Rekayasa Gempa Berbasis Kinerja. 2nd ed. Yogyakarta: ANDI. 